\title{
Program English Fun Activities untuk Mengembangkan Speaking Skills Siswa SDN Sukamulya
}

\author{
Meiliana Nurfitriani, Rahmat Permana, Yopa Taufik Saleh, Anggia Suci Pratiwi, \\ Budi Hendrawan, Mohammad Fahmi Nugraha \\ Prodi PGSD FKIP Universitas Muhammadiyah Tasikmalaya \\ Jl. Tamansari Km. 2,5 Mulyasari, Tamansari Kota Tasikmalaya \\ Email: meiliana.nurfitriani@umtas.ac.id
}

\begin{abstract}
Abstrak
Program English Fun Activities ini bertujuan untuk menciptakan suasana yang menyenangkan (fun) pada pembelajaran Bahasa Inggris di sekolah dasar, khususnya untuk mengembangkan kemampuan berbicara (speaking skills) siswa SDN Setiamulya. Bahasa Inggris merupakan salah satu mata pelajaran yang sangat penting untuk dikuasai oleh siswa namun kebanyakan siswa menganggap bahwa mata pelajaran ini sangat sulit untuk dikuasai. Cara pengucapan yang berbeda dengan penulisannya, makna yang sulit untuk dihafal, serta tata bahasa yang dianggap rumit menjadi tantangan sendiri bagi siswa sehingga mereka merasa bosan dan enggan untuk mempelajarinya. Untuk mengatasi hal ini diperlukan strategi khusus yakni dengan membuat program English fun activities. Program ini diikuti oleh siswa SDN Setiamulya, mulai dari kelas 4 sampai dengan kelas 6 selama 3 hari. Penyampaian pembelajaran Bahasa Inggris ini dilakukan dengan cara yang menyenangkan seperti permainan (games) berbahasa Inggris, menyanyi dan menari. Program ini berjalan dengan lancar, siswa sangat antusias belajar dan berperan aktif selama pembelajaran berlangsung. Program English fun activities ini membuktikan bahwa belajar Bahasa Inggris itu sangat mudah dan menyenangkan.
\end{abstract}

Kata Kunci: belajar bahasa inggris, speaking skills, English fun activities

\begin{abstract}
The English Fun Activities Program aims to create a fun atmosphere for learning English in elementary schools, specifically to develop students' speaking skills of SDN Setiamulya. English is one of the most important subjects to be mastered by students but most students assume that this subject is very difficult. The pronunciation is different from the writing, the meaning is difficult to be memorized, and grammar which is considered complicated becomes its own challenge for students so they feel bored and reluctant to learn it. To overcome this, a special strategy is needed, namely by creating English fun activities programs. The program was attended by SDN Setiamulya students, starting from grade 4 to grade 6 for 3 days. Submission of learning English is done in a fun way such as English games, singing and dancing. This program runs smoothly, students are very enthusiastic about learning and play an active role during learning. The English fun activities program proves that learning English is very easy and fun.
\end{abstract}

Keywords: learning English, speaking skills, English fun activities

\section{PENDAHULUAN}

Bahasa Inggris tidak hanya diajarkan di sekolah menengah, melainkan juga sudah diajarkan di sekolah dasar dan sederajat. Namun jangan sampai, pembelajaran bahasa Inggris 
hanya akan menjadi beban tambahan bagi siswa. Pada akhirnya siswa kurang berminat untuk mempelajari dan tidak bisa mengaplikasikan dalam kehidupan sehari-hari. Oleh karena itu, dibutuhkan peran guru yang bisa mendesain pembelajaran menjadi menarik dan menyenangkan serta dapat dipahami dengan mudah, sehingga akan menambah minat belajar siswa dalam pembelajaran Bahasa Inggris.

Asumsi kebanyakan siswa yang menganggap bahasa Inggris itu sulit menjadi hal yang menghambat siswa untuk belajar bahasa tersebut, banyaknya kosakata dan makna yang harus dihafal, cara pengucapan dan penulisan yang berbeda, serta tata bahasa yang dianggap rumit menjadikan bahasa tersebut sangat membosankan dan sulit dipahami. Siswa SD belum bisa konsentrasi penuh dan masih senang dengan hal-hal yang bersifat fun dan ringan, maka pembelajaran Bahasa Inggris yang menyenangkan menjadi kunci pembelajaran dapat diterima oleh siswa SD.

Guru merupakan aspek fundamental dalam proses pembelajaran, dalam hal ini perannya sangat penting dalam memandu proses pembelajaran tersebut. Namun, beberapa fenomena yang terjadi, bahwa beberapa guru Bahasa Inggris di beberapa sekolah dasar tidak mempunyai background knowledge Bahasa Inggris, namun hanya berbekal kemampuan dasar Bahasa Inggris pada waktu masih duduk dibangku kuliah atau schooling. Selain itu, ada beberapa guru yang terpaksa mengajar Bahasa Inggris dengan alasan tidak ada guru lain. Dari fenomena di atas, kami dosen Pendidikan Guru Sekolah Dasar tergugah untuk mengadakan kegiatan Program English Fun Activities di SDN Setiamulya, dengan harapan memberikan pembelajaran Bahasa Inggris yang menyenangkan dan mudah untuk dipahami serta diingat, khususnya dalam kemampuan berbicara. Program English Fun Activities ini bertujuan untuk menciptakan suasana yang menyenangkan (fun) pada pembelajaran Bahasa Inggris di sekolah dasar, khususnya untuk mengembangkan kemampuan berbicara (speaking skills) siswa SDN Setiamulya.

\section{METODE PELAKSANAAN}

Kegiatan program English fun activities ini dilaksanakan pada tanggal 18-20 Februari 2020. Adapun lokasi pelaksanaannya bertempat di SDN Setiamulya, Mulyasari, Kecamatan Tamansari Kota Tasikmalaya.

Program ini telah disepakati bersama dengan pihak sekolah dan dilaksanakan setelah jam istirahat selama kurang lebih 90 menit. Selama tiga hari tersebut, siswa diberikan materi Bahasa Inggris yang berbeda di setiap kelasnya, dengan kata lain satu materi untuk satu hari. Dengan demikian siswa diharapkan mampu menguasai beberapa materi dasar Bahasa Inggris, khususnya dalam keterampilan berbicara. Materi Bahasa Inggris yang diberikan di kelas 4 yaitu Introduction, Numbers, and Pets. Adapun materi yang diberikan di kelas 5 yaitu introduction, Things in the classroom and around school, and My family. Materi yang diberikan di kelas 6 yaitu introduction, describing people and object, direction and location.

\section{HASIL DAN PEMBAHASAN}

Program English fun activities yang dilaksanakan di SDN Setiamulya merupakan serangkaian kegiatan belajar Bahasa Inggris dengan cara-cara yang aktif, kreatif dan menyenangkan. Program ini lebih menekankan pada proses belajar itu sendiri menggunakan prinsip belajar sambil bermain. Pada program ini siswa tidak terlalu dibebani materi-materi Bahasa Inggris yang mereka anggap sangat sulit untuk dipelajari, namun tutor menyajikan materi tersebut dalam bentuk games, menyanyi dan menari, serta berdiskusi dan bekerjasama sehingga dalam proses belajar tersebut siswa terlibat aktif dan menikmati tahapan pembelajaran dengan menyenangkan. Program ini lebih fokus pada aktivitas oral 
yaitu speaking agar siswa dapat mempraktekkan secara langsung dan berlatih berbicara Bahasa Inggris serta dapat menggunakannya dalam kehidupan sehari-hari.

Program ini melibatkan beberapa mahasiswa yang berperan sebagai tutor. Adapun yang menjadi peserta dalam program ini adalah siswa kelas 4 sampai dengan kelas 6 SDN Setiamulya. Setiap kelas didampingi oleh 2 orang tutor agar siswa dapat dibimbing lebih maksimal sehingga diharapkan hasil belajarnya pun akan menjadi lebih maksimal.

Berikut merupakan rangkaian aktivitas yang telah dilaksanakan di kelas 4-6 SDN Setiamulya.

Tabel 1. Program English Fun Activities untuk Meningkatkan Speaking Skills Siswa SDN Setiamulya

\begin{tabular}{|c|c|c|c|}
\hline KELAS/TUTOR & $\begin{array}{c}\text { MATERI } \\
\text { PEMBELAJARAN }\end{array}$ & INDIKATOR & KEGIATAN \\
\hline $\begin{array}{c}4 \\
\text { ANDREANI } \\
\text { TRI }\end{array}$ & $\begin{array}{l}\text { 1. Greetings and } \\
\text { leave taking, } \\
\text { Introducing } \\
\text { oneself, asking } \\
\text { one's personal } \\
\text { data }\end{array}$ & $\begin{array}{l}\text { a. Siswa mampu } \\
\text { mengekspresikan } \\
\text { greeting dan leave } \\
\text { taking dalam } \\
\text { percakapan } \\
\text { sederhana } \\
\text { b. Mampu } \\
\text { memperkenalkan } \\
\text { diri dalam Bahasa } \\
\text { Inggris } \\
\text { c. Mampu } \\
\text { mengekspresikan } \\
\text { data diri seperti } \\
\text { hobi, cita-cita, } \\
\text { tempat tinggal, } \\
\text { dll. }\end{array}$ & $\begin{array}{l}\text { 1. Buat } 2 \text { tim dan } \\
\text { masing masing tim } \\
\text { harus berlomba } \\
\text { memperkenalkan } \\
\text { diri. } \\
\text { 2. Masing masing tim } \\
\text { melingkar. Lalu salah } \\
\text { satu } \\
\text { memperkenalkan } \\
\text { diri sambil } \\
\text { memegang bisa } \\
\text { bola.(tutor } \\
\text { memutar music } \\
\text { instrument yg slow } \\
\text { agar lebih relax) } \\
\text { 3. Bola tersebut lalu } \\
\text { dilempar ke teman } \\
\text { di sampingnya dan } \\
\text { harus } \\
\text { memperkenalkan } \\
\text { diri } \\
\text { memperkenalkan } \\
\text { teman sebelumnya. } \\
\text { Ex: hallo, my name is } \\
\text { David, I'm from } \\
\text { Ciamis, my hobby is } \\
\text { swimming.And he is } \\
\text { my friend, his name } \\
\text { is Andy. He's from } \\
\text { Tasikmalaya, and so } \\
\text { on. Lakukan hal tersebut } \\
\text { sampai semua } \\
\text { mendapat giliran }\end{array}$ \\
\hline
\end{tabular}




\begin{tabular}{|c|c|c|c|}
\hline \multirow[t]{4}{*}{ KELAS/TUTOR } & $\begin{array}{c}\text { MATERI } \\
\text { PEMBELAJARAN }\end{array}$ & INDIKATOR & KEGIATAN \\
\hline & & & $\begin{array}{l}\text { 5. Tim yang paling } \\
\text { cepat menyebutkan } \\
\text { nama/memperkenal } \\
\text { kan diri dia yang } \\
\text { menang. }\end{array}$ \\
\hline & 2. Numbers & $\begin{array}{l}\text { a. Mampu mengenal } \\
\text { dan menyebutkan } \\
\text { bilangan dalam } \\
\text { Bahasa Inggris } \\
\text { b. Mampu berhitung } \\
\text { menggunakan } \\
\text { Bahasa Inggris } \\
\text { c. Mampu } \\
\text { memahami jenis } \\
\text { jenis bilangan dan } \\
\text { menggunakannya } \\
\text { dalam percakapan } \\
\text { sederhana }\end{array}$ & $\begin{array}{l}\text { 1. Menyanyikan lagu } \\
\text { numbers } \\
\text { 2. Berikan materi } \\
\text { numbers dan } \\
\text { jenisnya:ordinal dan } \\
\text { cardinal } \\
\text { 3. Games: } 5 \text { boom } \\
\text { Siswa melingkar, } \\
\text { lalu berhitung } \\
\text { tetapi harus } \\
\text { mengatakan boom } \\
\text { pada angka } 5 \text { dan } \\
\text { kelipatannya, } \\
\text { sampai tersisa } 1 \\
\text { pemenang. } \\
\text { 4. Berikan materi } \\
\text { ordinal dan cardinal } \\
\text { numbers. } \\
\text { 5. Bermain peran } \\
\text { dengan } \\
\text { menggunakan } \\
\text { ordinal dan cardinal } \\
\text { numbers }\end{array}$ \\
\hline & 3. Pets & $\begin{array}{l}\text { a. Mampu mengenal } \\
\text { nama-nama } \\
\text { hewan peliharaan } \\
\text { di sekitar anak } \\
\text { b. Mampu } \\
\text { mendeskripsikan } \\
\text { hewan peliharaan } \\
\text { di sekitar anak }\end{array}$ & $\begin{array}{l}\text { 1. Bermain tebak } \\
\text { hewan: tutor } \\
\text { memberikan clue } \\
\text { dalam bentuk } \\
\text { kalimat tentang } \\
\text { hewan peliharaan } \\
\text { lalu meminta siswa } \\
\text { menebaknya, jika } \\
\text { dalam } 1 \text { kalimat } \\
\text { siswa blm bisa } \\
\text { menebak, tutor } \\
\text { memberikan clue } \\
\text { lagi sampai siswa } \\
\text { bisa menebak. } \\
\text { 2. Meminta siswa } \\
\text { bercerita tentang } \\
\text { hewan }\end{array}$ \\
\hline
\end{tabular}




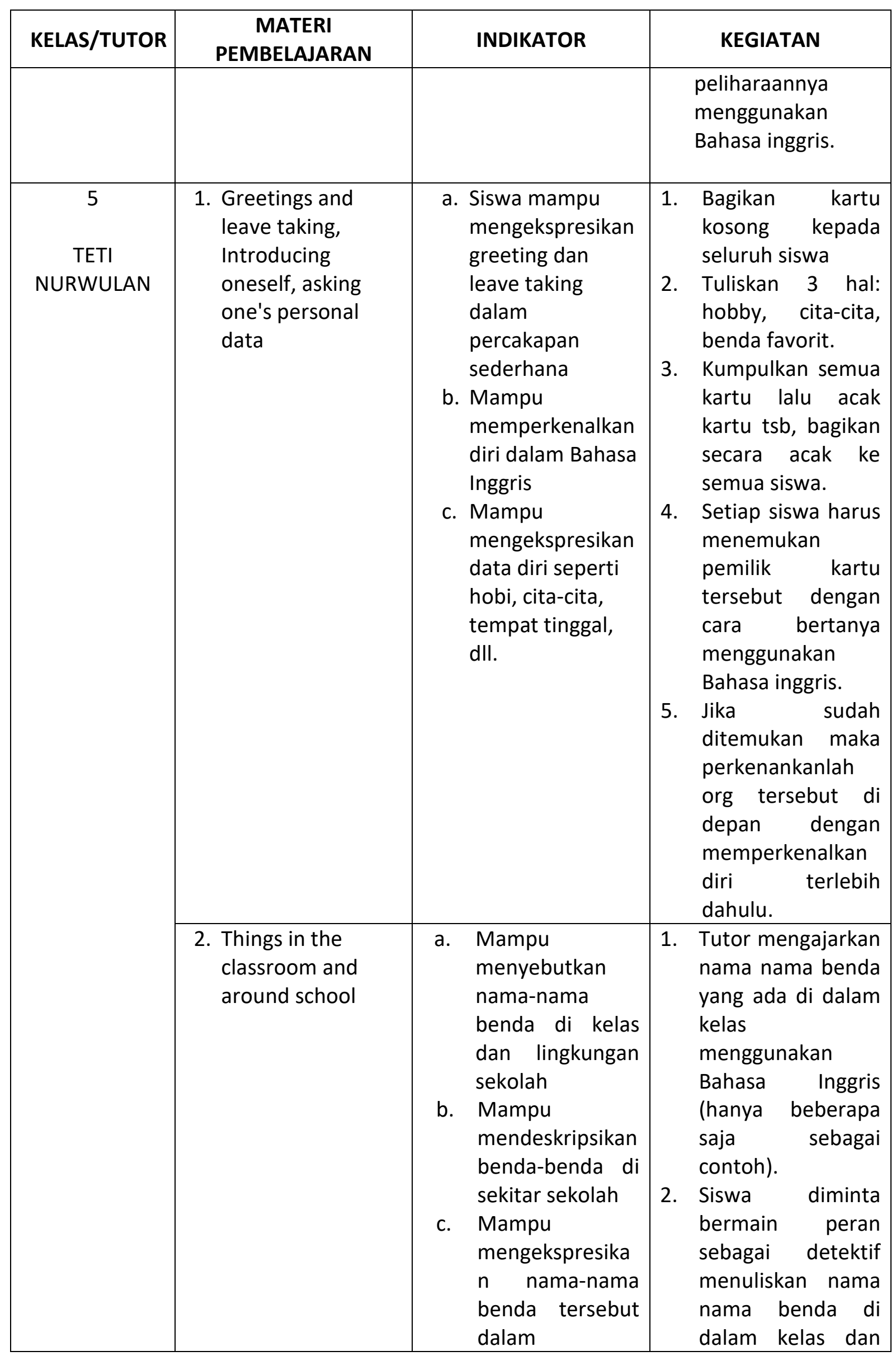




\begin{tabular}{|c|c|c|c|}
\hline KELAS/TUTOR & $\begin{array}{c}\text { MATERI } \\
\text { PEMBELAJARAN }\end{array}$ & INDIKATOR & KEGIATAN \\
\hline & & $\begin{array}{l}\text { percakapan } \\
\text { sederhana }\end{array}$ & 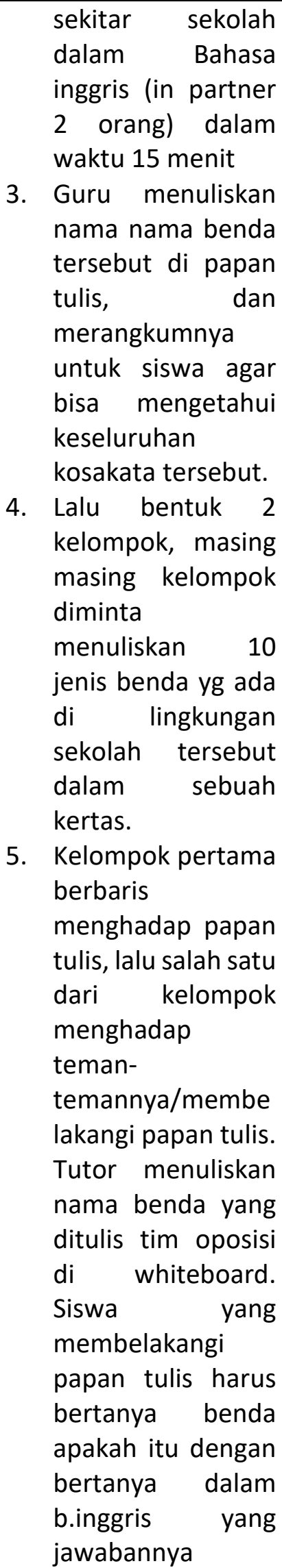 \\
\hline
\end{tabular}




\begin{tabular}{|c|c|c|c|}
\hline KELAS/TUTOR & $\begin{array}{c}\text { MATERI } \\
\text { PEMBELAJARAN }\end{array}$ & INDIKATOR & KEGIATAN \\
\hline & & & $\begin{array}{l}\text { yes/no.contoh: it's } \\
\text { used by students? } \\
\text { Maka teman yg } \\
\text { menghadap papan } \\
\text { tulis hanya boleh } \\
\text { menjawab yes/no. } \\
\text { berikan yang } \\
\text { pertanyaan sampai } \\
\text { siswa ditulis } \\
\text { membelakangi } \\
\text { papan tulis bisa } \\
\text { menebak benda } \\
\text { yang tersebut. Jika bisa } \\
\text { tersebak } \\
\text { menebak, maka } \\
\text { siswa yg mengantri } \\
\text { di depannya } \\
\text { bergantian posisi } \\
\text { sampai bisa } \\
\text { menjawab } 10 \\
\text { benda tersebut. } \\
\text { Siapa yg lebih dulu } \\
\text { menebak } 10 \text { nama } \\
\text { benda tersebut } \\
\text { maka kelompok itu } \\
\text { menang. }\end{array}$ \\
\hline & 3. My family & $\begin{array}{ll}\text { a. } & \text { Mampu } \\
& \text { menyebutkan } \\
\text { nama-nama } & \text { anggota keluarga } \\
\text { b. } & \text { Mampu } \\
\text { menggunakan } \\
\text { nama-nama } \\
\text { tersebut dalam } \\
\text { percakapan } \\
\text { sederhana }\end{array}$ & $\begin{array}{l}\text { 1. Menyanyikan lagu } \\
\text { baby finger dengan } \\
\text { menggunakan } \\
\text { boneka jari. } \\
\text { 2. Bercerita tentang } \\
\text { keluarganya.(perca } \\
\text { kapan sederhana } \\
\text { dalam Bahasa } \\
\text { inggris) } \\
\text { 3. Bermain peran } \\
\text { 4. Bermain } \\
\text { game:mendandani } \\
\text { siswa sesuai } \\
\text { karakter family } \\
\text { dengan } \\
\text { menggunakan } \\
\text { kertas yang diberi } \\
\text { double tip dan }\end{array}$ \\
\hline
\end{tabular}


Meiliana Nurfitriani, Rahmat Permana, Yopa Taufik Saleh, Anggia Suci Pratiwi,

Budi Hendrawan, Mohammad Fahmi Nugraha

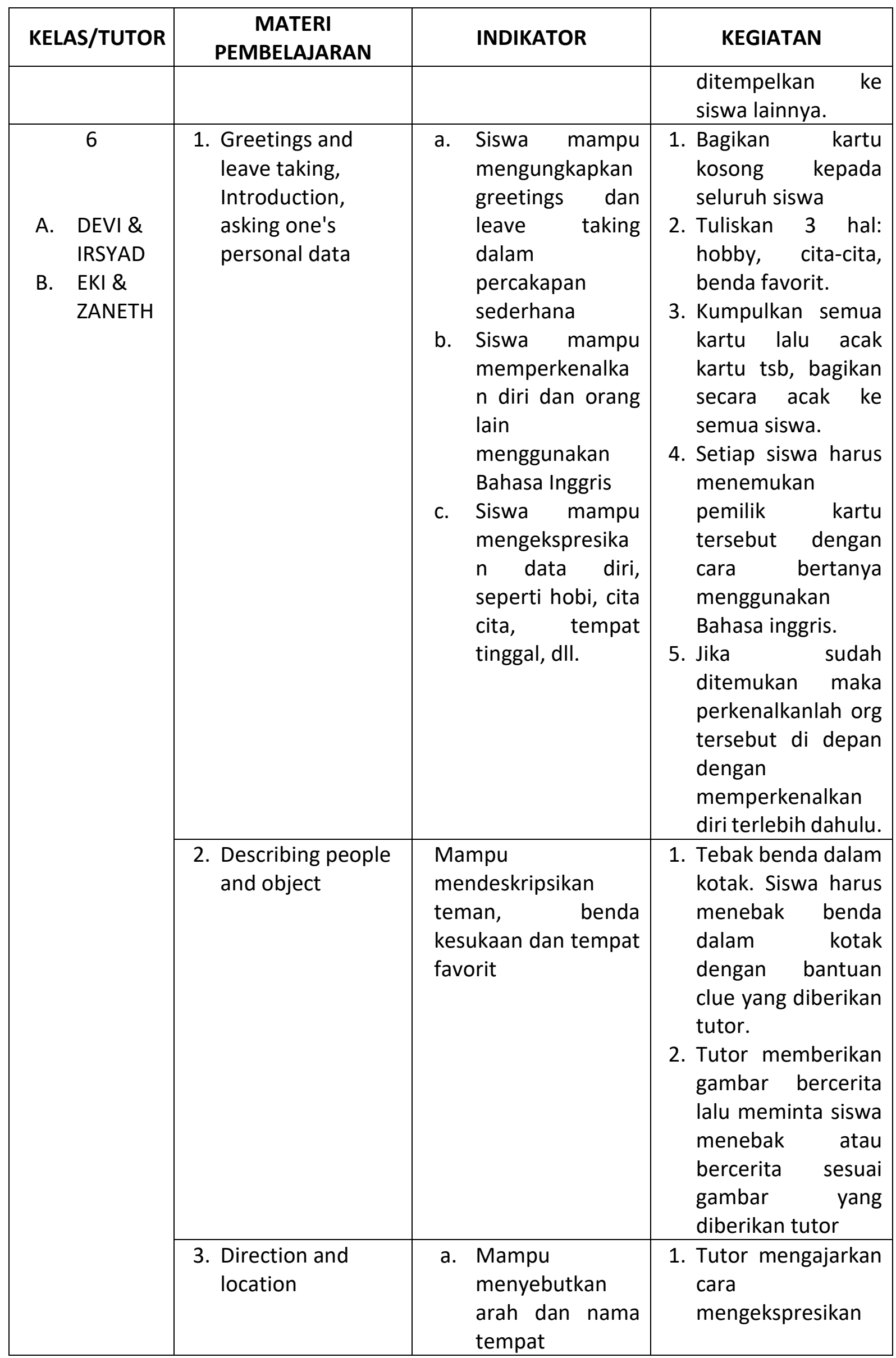




\begin{tabular}{|c|c|c|c|c|}
\hline KELAS/TUTOR & $\begin{array}{c}\text { MATERI } \\
\text { PEMBELAJARAN }\end{array}$ & & INDIKATOR & KEGIATAN \\
\hline & & & $\begin{array}{l}\text { Mampu } \\
\text { mengekspresika } \\
\mathrm{n} \text { petunjuk arah } \\
\text { dalam } \\
\text { percakapan } \\
\text { sederhana }\end{array}$ & $\begin{array}{l}\text { nama nama arah } \\
\text { dan lokasi } \\
\text { 2. Bermain games } \\
\text { menemukan harta } \\
\text { karun di halaman } \\
\text { sekolah }\end{array}$ \\
\hline
\end{tabular}

\section{KESIMPULAN}

Dari hasil program English fun activities yang telah dilaksanakan di SDN Setiamulya dapat diambil kesimpulan bahwa bahasa Inggris sebagai bahasa asing dapat dengan mudah dipelajari jika menggunakan metode belajar yang tepat, seperti menggunakan lagu atau permainan. Metode tersebut membuat siswa menjadi lebih bersemangat dan enjoy untuk belajar bahasa Inggris sehingga proses belajar bahasa Inggris pun menjadi lebih mudah.

\section{DAFTAR PUSTAKA}

Brewster, J., Ellis, G. \& Girard, D. (2003). The Primary English Teacher's Guide. London: Penguin English.

Cameron, L. (2001). Teaching Language to Young Learner. Cambridge: Cambridge University Press. 